\title{
Assessing Swedish Foundries Energy Management Program
}

\author{
Aida Sa ${ }^{1}$, Patrik Thollander ${ }^{2}$, Enrico Cagno ${ }^{3, *}$ and Majid Rafiee ${ }^{1}$ \\ 1 Department of Industrial Engineering, Sharif University of Technology, Tehran 11155-9414, Iran; \\ aida.salimnezhad@sharif.edu (A.S.); rafiee@sharif.edu (M.R.) \\ 2 Department of Management and Engineering, Division of Energy System, Linköping University, \\ 58183 Linköping, Sweden; patrik.thollander@liu.se \\ 3 Department of Management, Economics and Industrial Engineering, Politecnico di Milano, \\ via Lambruschini 4/B, 20156 Milano, Italy \\ * Correspondence: enrico.cagno@polimi.it; Tel.: +39-022-399-4054
}

Received: 3 September 2018; Accepted: 28 September 2018; Published: 16 October 2018

\begin{abstract}
With regard to increased sustainability, managers not only need to know WHAT is needed for their company to improve, but also HOW to do so in detail is equally important. Energy management (EnM) is a pillar to the transformation of industrial energy systems towards enhanced energy efficiency and increased sustainability. One way to develop more and improve EnM both practically and theoretically is to shed light on how the combination of techniques and operation can contribute to successful EnM. This paper, therefore, through investigation of 10 Swedish foundries aims to present the structure of the energy strategy and associated practices at first; second, to assess industry's EnM program and maturity level; and third, to identify and understand the nature of energy efficiency promoting factors within studied cases.
\end{abstract}

Keywords: energy management program; energy management assessment; foundry; industrial energy efficiency

\section{Introduction}

International agreements to control emissions and mitigate climate change along with energy price fluctuation and crises have elevated the importance of energy efficiency (EE) in the industrial sector, one of the main energy consumers in every society. Hence, it is important to study energy-intensive industries such as the foundry sector (a major energy-consuming industry and a strategic sector for the European economy) [1,2]. The international energy management standard 50001 came into force in 2011 based on the previous European standard, EN 16001, which was, in turn, based heavily on the Swedish standard used for the two program periods of the Swedish Voluntary Agreements Program, the PFE (Program for energy efficiency in energy-intensive industry). In 2012, a European standard for energy audits was launched, EN 16247, which was later followed by an international ISO 50002-standard in compliance with the ISO 50001 energy management standard. The above-mentioned energy management (EnM) and energy audit standards are the current foremost means of standardization tools for improving EE in industrial companies. Implementation of such standards are, in turn, supported by numerous international and national companies which are involved in certification and accreditation.

To improve EE in industry, long-term energy strategies and committed energy managers and people with real ambitions are crucial factors in spurring improved EE in industrial firms [3]. While several factors promote the efficient use of energy, there seems to be some barriers. EnM has been addressed in several scientific papers as a robust and efficient means to overcome such 
barriers. The term EnM has been used in various ways in the academic literature, yet there is still no cohesive definition [4]. The common view among many of scholars in definition of EnM is that they primarily concentrate on technologies and replacing or upgrading inefficient equipment. However, EnM also includes practices such as care, operation and maintenance of technology to maintain effective functioning. Apart from energy-related decision making, which is the very first step in EnM programs implementation, continuous work and improvement practices through energy performance measurement are the first requirements to implement successful in-house EnM [5,6]. It is important, therefore, to provide proper information about a given factory's overall energy performance state which not only leads to a better understanding of existing barriers, but it also helps to provide EnM and hint to introduce an optimization model [5,7]. Moreover, to have fundamental improvement results including lean thinking within company's energy-related strategy and see the company as a system and not separate processes to be analyzed is vital [3]. The most recent theoretical and empirical research studies about drivers and barriers can be found in Trianni et al. [8-14], for a more comprehensive view. As regards the foundry sector, the most recent comprehensive research about barriers can be found in Trianni et al. [15] and for drivers see Thollander et al. [2]. Meanwhile, previous policy researchers identified and classified a number of barriers to and drivers for EE in industries [16-18]. Two of these barriers, namely organizational and behavioral barriers, relate to the energy management practices (EnMPs) within the company. In general, however, the details of how an EnM program is practiced in a company have to a large extent remained unexplored $[1,7,19,20]$. Accordingly, the former barriers relate to the imprecise division of tasks and lack of financial resources, time and experienced personnel [21] while the latter barriers consist of personnel values and mindsets [22,23].

Police researchers addressed the improvement of EnMPs in companies as an important yet challenging issue. Johansson and Thollander [3] in a very recently published review paper formulated ten factors for EnMPs success namely (1) top management support; (2) long-term energy strategy; (3) A two-step energy plan; (4) An energy manager position; (5) Correct energy-cost allocation; (6) Clear key performance indicators; (7) Energy controllers among floor-level staff; (8) Education for employees; (9) Visualization; and (10) Energy competition. A combination of various policy measures has been recognized to affect industry, both directly and indirectly, together with a combination of voluntary and obligatory standards. This challenge is also due to a lack of clear EnMPs understanding and how these should be placed by organizations in order to improve EE. Sa et al. [24] define EnMPs as "total continuous or frequent managerial and technical actions in a company the aim of which is primarily to reduce energy cost or secure energy supply and secondarily to reduce pollution". Guidelines and different standards on EnM emphasize the importance of monitoring, assessing and enhancing performance of energy at process and system levels. However, for better results, managers need to assess their program to track the strength and weakness of their current energy plan. The reasons for this corresponds with the need to verify and evaluate the company's energy strategy and the current situation of the adopted practices together with assessing the company's policy, organizing, training, performance measurement, communication and investment maturity level, but unfortunately, this kind of empirical investigation has been left blank in academic literature. Therefore, the aim of this paper is to:

(1) Present the structure of the energy strategy and associated practices. The strategic plan deals not only with technical aspects but also with the funding, communication, education, and behavioral modification aspects of an EnM program (to see the table please refer to the [25] appendix section). According to Turner [26], developing a strategic plan with related practice items is the last but most important step in an organization's EnM program development, though this is where many stop.

(2) Assess industry's EnM program and maturity level, according to EnM matrix [27], which is presented by Sa et al. [26]. The EnM matrix gives a clear picture about strengths and weaknesses of industry's EnM program across six areas of EE measures such as policy, organization, training, performance measurement, communication and investment at site level. 
(3) Identify and understand the nature of all those factors that promote foundries to continue EE improvement more than other promoting factors.

\section{Industrial Energy Management Program}

EnM is a pillar of the transformation of industrial energy systems towards improved EE and increased sustainability. Moreover, it is important to become less carbon-intensive [28]. A strategic approach which includes a long-term energy strategy and top management support is an important element of a proper industrial in-house EnM program [29]. Indubitably, the program should be initiated by an initial energy audit of the company, along with installation of an appropriate monitoring system and a well-structured energy plan [1,29]. An energy program for industries, nowadays, goes beyond the traditional energy audit approach, thus making inclusion of EnMPs seem desirable [20]. Although EnMPs are important, it is challenging due to the industry's complexness that arises from the range of energy uses across processes, each having distinctive characteristics for their energy use. In addition, it should be considered that there are different production requirements based on the product, its quality, and other business factors [30]. Therefore, transparency as an industrial energy program as well as having more detailed assessment of EnMPs enable pros and cons to be spotted, which in turn enable managers to move towards a more efficient design [2]. To improve the energy performance, several EnM scenarios appear through the combination of different alternatives. The reason for the absence of specific optimal solution can be explained through factory's complexity and unique characteristics of each particular industrial unit. An optimization target becomes multi-objective intending to minimize $\mathrm{CO}_{2}$ emissions and maximize energy and cost efficiencies. Therefore, the maintenance of a balance between these criteria, and prioritizing the criteria (which can be energy performance, costs, and emission level) will lead to define optimized EnM scenario with respect to the factory's characteristics and ultimately, an optimum strategy will be found through the consideration of the priority for each particular case [31].

Therefore, the strategic characteristic of each practice is an elemental qualification which leads to be included in energy program related decision-making process [25].

\section{Method}

Considering the research aims described above, this study was carried out as a multiple case study of ten Swedish foundries. Case study research is a sufficient method once "how", "why", and "what" queries are being posed [32]. In addition, a multiple case study is more preferable to a single-case because of its robust analytical conclusions offer. Since in-house circumstances were to be explored, a smaller number of replications were needed [33]. The primary source for the analysis was a semi-structured interview. This allows researchers to structure the interview and keep a logical order. The interview, therefore, has been organized by open-ended questions, as well as other questions emerging from the dialogue between the interviewer and each interviewee, in order to collect open comments and secondary data as suggested by [34].

\subsection{Foundry Industry}

Foundry, as an industry with differentiated and diverse characteristics, produces finished castings through melting ferrous and/or non-ferrous metals, depending to the type of the foundry and alloys as well, and reshapes them into components which will be in need of extra treatment to produce a final product. The European foundry industry is the third largest producer for ferrous and second largest for non-ferrous castings in the world [34]. The annual production of castings in the enlarged European Union, including United Kingdom and Turkey, in 2015 amounts to 11.4 million tons of ferrous and 4 million tons of non-ferrous castings [35]. The main markets for the foundry industry are the automotive (with about $50 \%$ of market share), general engineering (with about $30 \%$ of market share) and construction (with $10 \%$ of the market share) sectors [34]. A typical modern casting 
process includes variety of activities namely: melting, alloying, molding, pouring, solidification, and completing procedure.

Within the academic literature, a number of papers focused on the EE and its improvement methods (e.g., material removal processes) for manufacturing processes [36]. However, these methods are not generalized to include castings, as one of most energy intensive and challenging processes, and its related energy use amount. The EE of a casting facility largely depends on the efficiency of its heat treating and melting performance. Estimations show that heat treating and melting use over $60 \%$ of the processes' total energy mentioning that there are huge capacity for the metal casting industry to apply the best EnMPs which will bring great chance for energy saving, and as a result, it improves a company's EE performance level [37].

\subsection{Swedish Foundry Industry}

Researches on foundry industry in some European countries indicate that the Swedish industry has largely depend on the use of electricity [38]. The focus of Swedish foundry industry is mainly on the production of advanced iron and steel grades, which are specially produced for domestic markets [39]. According to the Swedish Foundry Association [40], annual production in Sweden amounts to 325,000 tons of castings of which $76 \%$ are iron, $18 \%$ non-ferrous and $6 \%$ steel resulting in an aggregated annual energy use of about 1 TWh [40]. In all studied cases, electricity was the main energy carrier and in some cases district heating was used to cover the heating needs. LPG, which is used to preheat the ladles, devotes a small part of energy carrier of the 10 studied foundries. However, due to confidentiality reasons, there are not lots of accessible printed information and data on energy, material and emissions are not available for public [34]. Moreover, collecting data from the casting foundry sector faces a number of challenges the reason of which can be explained through the application of different approaches of each foundry. Thus, it is possible that the energy use would vary among variety of foundries, even if they produce same products [41]. The embedded energy is adopted as energy input data collection to avoid existing energy related data collection challenges. Embedded energy is defined as the "sum of the all energy required to produce products or provide services" [37]. Meanwhile, questions related to the existence of leakage and waste control, from energy point of view, devices and existence of documentation of energy use trend about the main energy user equipment within the company were asked from interviewees and site control, also, was carried out.

In the manufacturing chain, for more durable goods, metal castings are one of the first steps in the value-adding process. Castings of iron, steel, light metals, and other metals are made in units that may be either an independent or a part of the production line. Preparation of raw materials, metal melting, molds preparation, casting and finishing are the main steps of production. Presently, electric induction furnaces are used to melt the metals. In the next step, molten metal will be poured into the mold by using ladles or other pouring devices. Nevertheless, the automatically controlled pouring process is often used by large foundries. Finishing processes include fettling removals from the casting of the gating system, fins, and feeders. All the mentioned steps are accomplished by cutting, blasting, grinding, and chiseling. Molten metal treatment and melting itself, as well as molding, shakeout, cleaning and after-treatment, are generally of greatest emission concerns. To reduce, control, and keep the emissions as low as possible, it is essential to implement technical measures (e.g., index of energy use per standard unit). The rapid increase of natural gas prices together with deregulation of the electricity market have highlighted the necessity of addressing EE issues.

As the foundry industry is an energy-intensive industry, there is considerable focus on its energy end-use and ways to reduce and save energy. The majority of energy use in foundries goes into melting furnaces A new twin power furnace with lid and capacity of 11 tons has optimal levels of about $525 \mathrm{kWh}$ in a one-hour melting time. However, this amount changes to $900 \mathrm{kWh}$ for melting divisions using induction furnace without lid [42]. Being highly dependent on energy-intensive industries for countries such as Sweden raises the sensitivity of working on EE improvement. However, the result of this study together with results of previous researchers (e.g., Solding and Thollander [43]) reveal 
that resistance to new technology, new working method and aids, which are the main target of energy management programs, is significant among Swedish foundries.

\subsection{Research Methods}

As it is presented in Figure 1, developing a case study research in small/medium (five companies) and large size (five companies) companies is the main approach of current paper to answer the study objectives. To make a list of foundries for investigation, 17 foundries have been chosen among previously studied foundries and request email with short explanation about the research was sent to each contact person. 10 out of 17 (mixture of ferrous and non-ferrous foundries) showed interest or asked for further explanation. The study was carried out using semi-structured questionnaire and interviewing two persons, one from top management and the other one from energy group, from each case (for around two hours) about the EnMPs, EnM program, the company's energy-related targets and motivating factors. The content of the interviews empowered the researchers to recognize the adopted practices in each case. Thollander and Ottosson [18] classified EE drivers for pulp and paper industry into market related (M1 to M3), policy instruments (P1 to P15), and behavioral and organizational (O1 to O10) driving forces. In this study the same classification has been chosen to identify which drivers among all would promote continuous improvement of EE within Swedish foundries. During the interviews, the energy manager and/or companies' energy manager representatives were asked to mark, and rate factors shown in Figure 2, which represents EE promoting factors for improved EE on a scale of 0 : not important at all to 4 : strongly important. The assessment of maturity matrix has been done to project the current state of the EnM program for each foundry. Policy, organization, training, performance measurement, communication and investment are six aspects in maturity matrix, where users could rate their EnM program on a scale of 0: not important at all to 4: strongly important. The matrix enables a deeper understanding of the EnM and therefore, reflects a wider set of solutions to maintain EE improvement than just technology (the default solution for many). This tool is also a precise way to identify where barriers might exist in an organization.



Figure 1. Research design. 


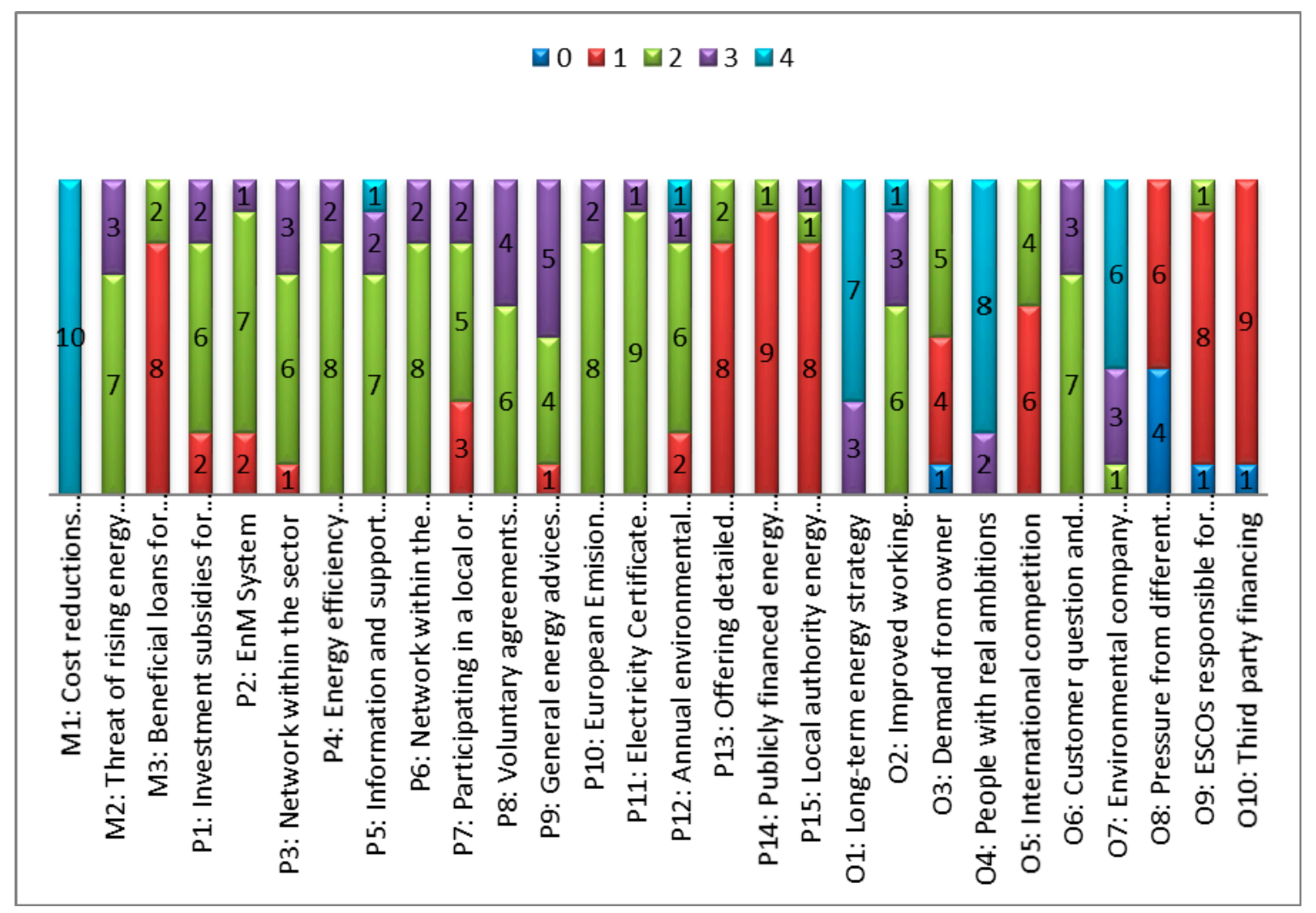

Figure 2. EE promoting factors (inspired from Thollander and Ottosson [18] and Brunke et al. [13]). Note: M1: Cost reduction resulting from low energy use; M2: Threat of rising energy prices; M3: Beneficial loans for EE investments; P1: Investment subsidies for EE technologies; P2: EnM system; P3: Network within the sector; P4: EE enablers such as energy auditing; P5: Information and support through the Swedish forest industries; P6: Network within the company; P7: Participating in a local or international energy programs; P8: Voluntary agreements to improve EE; P9: General energy advices from policy makers; P10: European Emission Trading Scheme (EU ETS); P11: Electricity Certificate System (ECS); P12: Annual environmental report to the Swedish county administrative board including an energy plan; P13: Offering detailed support from energy experts; P14: Publicly financed energy audits by energy consultant/sector organizations; P15: Local authority energy consultancy; O1: Long-term energy strategy; O2: Improved working conditions; O3: Demand from owner; O4: People with real ambitions; O5: International competition; O6: Customer question and interest to mitigate higher utility bills and environmental concerns; O7: Environmental company profile; O8: Pressure from different non-governmental organizations (NGOs); O9: ESCOs responsible for operation and maintenance of the buildings; O10: Third-party financing (TPF).

In addition to the interview, extensive document research (industry statistics, annual reports, and government environmental regulation reports) is done to examine and cross-check qualitative data to increase research validity [44] (look Figure 1).

Finally, the ordinary least squares (OLS) model (always with $p$-value of $\left({ }^{*} p<0.10,{ }^{* *} p<0.05\right.$, *** $p<0.01)$ ) is used to find the correlation between EnM program and EnMPs adoption. Also, it is used to present the correlation of EnM program and the level of each aspect of EnM matrix.

\section{Results and Discussion}

There are opportunities for EE improvement in all areas of a single foundry like melting, molding, ventilation, compressed air, lighting and heating, ventilation, and air conditioning (HVAC). However, according to a current investigation, melting is the biggest area for improvements [45]. Melting, by itself, accounts for almost 50\% of a company's total end-use energy [7]. Table 1 shows the practices 
identified within selected foundries and their strategic roles through EE improvement in details according to Turner's [26] energy strategy classification. Also, the number of companies which chose the referenced practices in their energy program is presented (see Table 1).

Table 1. Adopted EnMPs by 10 foundries (A to J represents 1 to 10 foundries).

\begin{tabular}{|c|c|c|c|c|c|c|c|c|c|c|c|}
\hline \multirow[b]{2}{*}{ Practices } & \multirow{2}{*}{$\begin{array}{l}\mathbf{L} \\
\mathbf{A}\end{array}$} & \multicolumn{2}{|c|}{ SM } & \multirow[b]{2}{*}{ D } & \multicolumn{2}{|c|}{ SM } & \multirow[b]{2}{*}{ G } & \multicolumn{2}{|l|}{$\mathbf{L}$} & \multicolumn{2}{|c|}{ SM } \\
\hline & & B & C & & $\mathbf{E}$ & $\mathbf{F}$ & & $\mathbf{H}$ & I & $\mathbf{J}$ & Sum \\
\hline R1 & $x$ & $X$ & - & $x$ & - & - & $X$ & - & $X$ & $x$ & \\
\hline $\mathrm{R} 2$ & $x$ & $x$ & $x$ & $x$ & $x$ & $x$ & $X$ & $x$ & $X$ & $x$ & \\
\hline R3 & $X$ & - & - & - & - & - & $X$ & $x$ & $X$ & $X$ & 10 \\
\hline $\mathrm{R} 4$ & - & - & - & - & - & - & - & - & - & - & \\
\hline R5 & $X$ & $X$ & $X$ & $X$ & $x$ & $x$ & $X$ & $x$ & $X$ & $x$ & \\
\hline E1 & $x$ & - & - & - & $x$ & - & $X$ & - & - & - & \\
\hline E2 & $x$ & - & - & - & - & - & $X$ & - & - & - & \\
\hline E3 & $x$ & - & - & - & - & - & - & - & - & - & 3 \\
\hline $\mathrm{E} 4$ & - & - & - & - & - & - & - & - & - & - & \\
\hline L1 & - & - & - & - & - & - & - & - & - & - & \\
\hline L2 & $x$ & - & - & - & - & - & $X$ & - & - & - & 2 \\
\hline L3 & $x$ & - & - & - & - & - & $X$ & - & - & - & \\
\hline F1 & - & - & - & - & - & - & $X$ & - & - & - & \\
\hline $\mathrm{F} 2$ & - & - & - & - & - & - & - & - & - & - & \\
\hline F3 & - & - & - & - & - & - & - & - & - & - & 1 \\
\hline $\mathrm{F} 4$ & - & - & - & - & - & - & - & - & - & - & \\
\hline A1 & $x$ & - & - & - & - & - & - & - & - & - & \\
\hline A2 & $x$ & - & - & - & - & - & - & - & - & - & \\
\hline A3 & - & - & - & - & - & - & - & - & - & - & 2 \\
\hline A4 & $X$ & - & - & - & - & - & $X$ & - & $x$ & - & \\
\hline Sum & 12 & 3 & 2 & 3 & 3 & 2 & 10 & 3 & 5 & 4 & \\
\hline
\end{tabular}

Note: SM and L accordingly represent small/medium and large size foundries. Code R1 to R5, E1 to E4, L1 to L3, F1 to F4 and A1 to A4 are accordingly practices related to Reliability, Efficiency, Low cost, Funding and Awareness strategies which can be fined more in detail in a paper written by Sa et al. [25].

Turner [26] states that a successful EnM program spreads its practices in all classified strategies. However, as seen in Table 1, almost all companies have a poor action plan on EE, low cost, funding, and awareness. Only company A and company $\mathrm{G}$ have distributed their practices across all classified energy strategies. Almost $80 \%$ of the studied foundries do not have a proper EnM control system, any sub-metering system and there are very few practices for organizational EE, which is recognized as one of the two practice-related barriers and at the same time both of them are recognized as most important measure and facilitator for improved EE in the literature. Although literature indicates the important role of long-term strategy, such long-term energy strategies are lacking within the companies' total energy strategy. About one in ten stated that they have used Energy Performance Contracting (EPC) and Third-Party Financing (TPF). Among the studied cases, only two out of ten have conducted an energy audit which is the very first step in developing EnM program.

If improvement is the primary question, assessing the current status would be the foremost step to see the intensity and weak aspects of the plan. The EnM assessment model enables managers to deliver a clear picture about the current state of the company's EnM program. Table 2 clearly presents the maturity level of an EnM program for each foundry. 
Table 2. EnM assessment model results.

\begin{tabular}{cccccccccccc}
\hline Size & L & SM & SM & L & SM & SM & L & L & L & SM \\
\hline Companies & A & B & C & D & E & F & G & H & I & J \\
\hline Policy & 4 & 1 & 1 & 3 & 1 & 1 & 4 & 1 & 2 & 1 \\
Organization & 4 & 2 & 2 & 3 & 2 & 2 & 3 & 2 & 2 & 2 \\
Training & 2 & 0 & 0 & 0 & 0 & 0 & 0 & 0 & 0 & 0 \\
Performance measurement & 4 & 0 & 2 & 2 & 0 & 0 & 4 & 2 & 2 & 2 \\
Communication & 4 & 2 & 2 & 2 & 2 & 2 & 3 & 2 & 1 & 2 \\
Investment & 3 & 2 & 2 & 2 & 2 & 2 & 3 & 2 & 2 & 2 \\
\hline Average & Tends & Tends & Tends & \multirow{2}{*}{2} & Tends & Tends & Tends & Tends & Tends & Tends \\
& to 4 & to 2 & to 2 & & to 2 & to 2 & to 3 & to 2 & to 2 & to 2 \\
\hline
\end{tabular}

Note: L represents large size companies and SM represents small/medium companies. The classification of grades for each assessment can be fined in a paper written by Sa et al. [25].

According to the results of the assessment model (Table 2), only two large foundries positioned their EnM maturity level relatively in 4 and 3 while all the others are positioned in a mode of 2 and average maturity level for all 10 foundries fell in a mode of 2.3. A comparison between Tables 1 and 2 illustrates the results of Tables 3 and 4. Wherever there are no EnMPs the maturity level decreases. The main weaknesses for all foundries, except company A, seem to have stemmed from training, performance measurement, energy policy action plan, and investment. Measuring EE performance and energy auditing of equipment, processes and factories is the starting point and indispensable step in effective EnM [5]. However, the variety and complexity of the energy use processes result in difficulty to establish an energy performance measurement and energy audit system, which is recognized as an effective analysis methodology and management tool [46], because of the lack of an effective method. It is essentially important for EnM to synthetically consider different production demands or influential factors related to the energy performance. So, the systematic, accurate and transparent on-line energy data of the production process and equipment becomes the essential condition of EnM and conservation [47]. An information system in several areas may provide opportunity to set goals, track performance and communicate the results even if it speaks about a particular and exclusive result story. Therefore, this need highlights the importance of connectivity within the sector and with similar sectors outside. Connectivity could help in monitoring energy consumption and it could be exploited to reduce energy consumption in the foundry sector.

Table 3. Regression results (A) ${ }^{\text {a }}$.

\begin{tabular}{cccccccc}
\hline & $\mathbf{( 1 )}$ & $\mathbf{( 2 )}$ & $\mathbf{( 3 )}$ & $\mathbf{( 4 )}$ & $\mathbf{( 5 )}$ & $\mathbf{( 6 )}$ & $\mathbf{( 7 )}$ \\
\cline { 2 - 8 } & Policy & Organizing & Training & $\begin{array}{c}\text { Performance } \\
\text { Measurement }\end{array}$ & Communication & Investment & $\begin{array}{c}\text { Matrix } \\
\text { Level }\end{array}$ \\
\hline \multirow{3}{*}{ EnM program } & $\mathrm{b} / \mathrm{se}$ & $\mathrm{b} / \mathrm{se}$ & $\mathrm{b} / \mathrm{se}$ & $\mathrm{b} / \mathrm{se}$ & $\mathrm{b} / \mathrm{se}$ & $\mathrm{b} / \mathrm{se}$ & $\mathrm{b} / \mathrm{se}$ \\
& $2.63^{* * *}$ & $1.36^{* * *}$ & $1.00^{* *}$ & $3.50^{* * *}$ & $1.63^{* * *}$ & 1.00 & $1.50^{* * *}$ \\
Constant & $(0.55)$ & $(0.33)$ & $(0.40)$ & $(0.69)$ & $(0.33)$ & $()$. & $(0.19)$ \\
& $1.38^{* * * *}$ & $2.13^{* * *}$ & 0.00 & 0.50 & $1.88^{* * *}$ & 2.00 & $2.00^{* * * *}$ \\
$\mathrm{~N}$ & $(0.25)$ & $(0.15)$ & $(0.18)$ & $(0.31)$ & $(0.15)$ & $()$. & $(0.09)$ \\
r2 & 10 & 10 & 10 & 10 & 10 & 10 & 10 \\
F & 0.74 & 0.69 & 0.44 & 0.77 & 0.75 & 1 & 0.88 \\
r2_a & 22.76 & 17.60 & 6.40 & 26.13 & 24.58 &. & 57.60 \\
L1 & 0.71 & 0.65 & 0.38 & 0.74 & 0.72 & 1.00 & 0.86 \\
\hline & -9.45 & -4.27 & -6.14 & -11.64 & -4.27 & & 0.79 \\
\hline
\end{tabular}


Table 4. Regression Model (B) ${ }^{\text {a }}$.

\begin{tabular}{cccccc}
\hline & $\mathbf{( 1 )}$ & $\mathbf{( 2 )}$ & $\mathbf{( 3 )}$ & $\mathbf{( 4 )}$ & $\mathbf{( 5 )}$ \\
\cline { 2 - 6 } & Reliability & Energy Efficiency & Low-Cost & Funding & Awareness \\
\hline \multirow{3}{*}{ EnM program } & $\mathrm{b} / \mathrm{se}$ & $\mathrm{b} / \mathrm{se}$ & $\mathrm{b} / \mathrm{se}$ & $\mathrm{b} / \mathrm{se}$ & $\mathrm{b} / \mathrm{se}$ \\
& 1.13 & $2.38^{* * *}$ & 2.00 & $0.50 * *$ & $1.38^{*}$ \\
Constant & $(0.62)$ & $(0.33)$ & $()$. & $(0.19)$ & $(0.65)$ \\
& $2.88^{* * *}$ & 0.13 & 0.00 & 0.00 & 0.13 \\
$\mathrm{~N}$ & $(0.28)$ & $(0.15)$ & $()$. & $(0.09)$ & $(0.29)$ \\
r2 & 10 & 10 & 10 & 10 & 10 \\
$\mathrm{~F}$ & 0.29 & 0.87 & 1 & 0.44 & 0.36 \\
r2_a & 3.32 & 52.51 &. & 6.40 & 4.50 \\
$\mathrm{Ll}$ & 0.21 & 0.85 & 1.00 & 0.38 & 0.28 \\
& -10.59 & -4.26 & & 0.78 & -11.09 \\
\hline
\end{tabular}

Given the huge emphasis in literature on the influential role of energy service provider companies (ESCOs) on improved EE, among all studied cases, only two foundries of large size addressed ESCOs, only partially in their entire EnM program. Others disregarded so due to lack of trust, lack of information, and the complexity of the industry itself. In almost all cases, it was observed that lack of metrics hampers the next implementation when projects are conducted. This can be exclusively explained through the barrier model. Technology-oriented measures combined with operational measures can be a sufficient program to have successful EnM program [20]. Moreover, without top management support and interest, energy-saving investment decisions would not be made.

Through the results from Tables 1 and 2, OLS model is set in Tables 3 and 4 to reflect the correlation between EnM programs and each item of Table 1 respectively and the rate of each practice in Table 4.

It is clear that the relation between EnM program and each item of EnM matrix is strongly positive. Also, results from Table 4 show significant strong relationship between EnM program and EE practices, low cost, funding and awareness, the areas from which almost all of the barriers arise. The results, once again, demonstrate the strategic role of EnM in improved EE within industry.

Results (see Figure 2) show that the most important driver for the adoption of EnMPs is cost reduction resulting from lower energy use, as it has a mode of 4 (strongly important) from all 10 foundries. This result is largely in line with the findings of an investigation conducted by Johansson and Thollander [3]. People with real ambition with a mode of 4 from eight foundries is the second important promoting factor, which also has almost the same importance level in studies by Venmas [48] and Thollander and Ottosson [17]. On the contrary, third-party financing together with a publicly financed energy audit by a technical consultant with a mode of 1 (not important) from nine companies has the lowest level of importance to promote EE among study cases.

Figure 2 shows that there are promoting factors from different perspectives such as market related (M1 to M3), policy related (P1 to P15), and organizational and behavioral related (O1 to O10), which push and motivate industries more and more to adopt EnMPs to continue the EE improvements. Figure 2 shows the EE-promoting factors in detail.

From all that is discussed here, one question stands out from the content: since EE projects are profitable for the companies, why do not EnM programs draw widespread support, in all their energy strategy programs, from top managers and why are not they adopted? The most likely justification for this would be that economic factors matter since in our studied cases there were programs which were profitable theoretically, but in practice, they were not adopted. According to the result shown in Table 3, practices with reliable strategic characteristics are mainly adopted, rather than other energy strategy programs which received a quite low level of adoption for their related practices. Apparently, this is contrary to capital investment theory. Although such a claim might seem challenging, the need for further investigation about determining factors in energy investment decision-making is highlighted. It matters who is attending energy-related decision making meeting owing to the fact 
that anyone would see the recommended program from their professional perspective and/or EE experience. Finally, by overlaying the energy saving potentials and/or opportunities with the related economic, technical and organizational barriers, against the current EU EE policy framework, the study recommends the following intervening measurement potentials that could address these barriers and further encourages energy saving opportunities:

1. Promote the mandatory need for implementation of EnM system for large energy-intensive companies;

Implementation of an EnM system is useful to characterize and identify energy saving potentials and gain long-term benefits both economically and socially. Statistically, through better energy management, companies can save $10-30 \%$ of their energy consumption and make reductions on their costs [49,50]. Implementation of environmental management systems based on EN ISO 14001:1996 [51] or the EU Eco-management and audit scheme (EMAS) based on EN ISO 14001 [52] are two well-known examples which implemented in several European Union's organizations.

2. Mandatory implementation of sub-metering and performance monitoring requirement for significant energy using equipment; successful EnM system requires detailed and accurate information on how and where energy is being used. Metering, sub-metering and monitoring are the most essential and key functions of an EnM system in which they provide accurate real-time and actual, estimation-free, energy consumption data. Moreover, they facilitate the energy usage data comparison across the similar equipment and over time. Additionally, through performance monitoring, it is feasible to identify and eliminate wasted energy and early access to those equipment that need maintenance before critical equipment fails.

3. Promote the need for energy managers by definition within large and energy-intensive companies.

\section{Conclusions}

The best environmental and/or EE performance is normally acceded by the assembling of the advanced technology and its effective and efficient functioning. Therefore, not only technology is important but also knowledge, technique and the approach in which the installation is designed, built, maintained, and operated is crucial. An EnM system is a tool that energy manager can use to sustain aforementioned issues in a systematic way. Moreover, an EnM system includes, defines and explains the organizational structure, responsibilities, practices, procedures, processes and resources for developing, implementing, maintaining, reviewing and monitoring the environmental policy. It becomes most effective and efficient if EnM systems form an inseparable and substantial part of the overall management and operation of an installation.

Absence of EnM system within the organizations structure has shown up in almost all studied cases which in turn caused imperfect EnM program implementation. Lack of proper EnM programs, by definition, within an in-house energy program caused the poor level of EnMPs to be widespread as well as a generally low maturity level. The investigation has shown that more than half of the studied cases lack a long-term energy strategy, a sub-metering system, or a proper EnM control system. Furthermore, lack of information about and trust in ESCOs through the company's EE improvement program is highlighted among selected Swedish foundries. Comparisons with previous literature and the result of the current study showed that drivers with a high EE promoting level sometimes act as barriers. Therefore, this paper, based on the adopted highest success level and the choice of evaluation method applied in the conducted research, concludes that the sustainability target will be hard to achieve if managers are not committed enough to develop a proper and comprehensive system to follow EnM program targets in their agenda. Moreover, it would be difficult to achieve if managers do not tie energy targets to the company's overall target and/or strategy.

In current study, embedded energy is adopted as data collection method to avoid difficulties in the collection of energy input data. Meanwhile, existence of leakage tracking system, waste control devices and existence of documentation of energy use trend for major energy user equipment within the 
company were controlled. However, further researches on various electrical and technical parameters are suggested. Finally, results also call out the need for an information system in several areas to set targets, explore performance and deliver the results even if it speaks about a particular and exclusive result story.

Author Contributions: Investigation, A.S., E.C.; Methodology, A.S., P.T.; Writing—original draft, A.S.; Writing — review and editing, E.C., M.R., P.T., A.S.

Funding: This research received no external funding.

Acknowledgments: Authors would like kindly thank the respondents at the studied companies for giving freely of their time to answer the questions.

Conflicts of Interest: The authors declare no conflict of interest.

\section{References}

1. Thollander, P.; Ottosson, M. Energy management practices in Swedish energy-intensive industries. J. Clean. Prod. 2010, 18, 1125-1133. [CrossRef]

2. Thollander, P.; Backlund, S.; Trianni, A.; Cagno, E. Beyond barriers-A case study on driving forces for improved energy efficiency in the foundry industries in Finland, France, Germany, Italy, Poland, Spain, and Sweden. Appl. Energy 2013, 111, 636-643. [CrossRef]

3. Johansson, M.T.; Thollander, P. A review of barriers to and driving forces for improved energy efficiency in Swedish industry-recommendations for successful in-house energy management. Renew. Sustain. Energy Rev. 2018, 82, 618-628. [CrossRef]

4. Schulze, M.; Nehler, H.; Ottosson, M.; Thollander, P. Energy management in industry-A systematic review of previous findings and an integrative conceptual framework. J. Clean. Prod. 2016, 112, 3692-3708. [CrossRef]

5. May, G.; Barletta, I.; Stahl, B.; Taisch, M. Energy management in production: A novel method to develop key performance indicators for improving energy efficiency. Appl. Energy 2015, 149, 46-61. [CrossRef]

6. Gordić, D.; Babić, M.; Jovičić, N.; Šušteršič, V.; Končalović, D.; Jelić, D. Development of energy management system-Case study of Serbian car manufacturer. Energy Convers. Manag. 2010, 51, 2783-2790. [CrossRef]

7. Thollander, P.; Palm, J. Industrial energy management decision making for improved energy efficiency—Strategic system perspectives and situated action in combination. Energies 2015, 8, 5694-5703. [CrossRef]

8. Trianni, A.; Cagno, E.; Marchesani, F.; Spallina, G. Classification of Drivers for Industrial Energy Efficiency and Effect on the Barriers Affecting the Investment Decision-Making Process. Energy Effic. 2017, 10, 199-215. [CrossRef]

9. Cagno, E.; Trianni, A.; Spallina, V.; Marchesani, F. Drivers for Industrial Energy Efficiency: An Investigation among Manufacturing Medium-sized Enterprises. Energy Effic. 2017, 10, 855-869. [CrossRef]

10. Cagno, E.; Trianni, A. Exploring drivers for energy efficiency within small and medium-sized enterprises: First evidences from Italian manufacturing enterprises. Appl. Energy 2013, 104, 276-285. [CrossRef]

11. Cagno, E.; Worrell, E.; Trianni, A.; Pugliese, G. A Novel Approach for Barriers to Industrial Energy Efficiency. Renew. Sustain. Energy Rev. 2013, 19, 290-308. [CrossRef]

12. Cagno, E.; Trianni, A. Evaluating the Barriers to Specific Industrial Energy Efficiency Measures: An Exploratory Study in Small and Medium-sized Enterprises. J. Clean. Prod. 2014, 82, 70-83. [CrossRef]

13. Brunke, J.C.; Johansson, M.; Thollander, P. Empirical investigation of barriers and drivers to the adoption of energy conservation measures, energy management practices and energy services in the Swedish iron and steel industry. J. Clean. Prod. 2014, 84, 509-525. [CrossRef]

14. Trianni, A.; Cagno, E.; Farné, S. Barriers, drivers and decision-making process for industrial energy efficiency: A broad study among manufacturing small and medium-sized enterprises. Appl. Energy 2016, 162, 1537-1551. [CrossRef]

15. Trianni, A.; Cagno, E.; Thollander, P.; Backlund, S. Barriers to industrial energy efficiency in foundries: A European comparison. J. Clean. Prod. 2013, 40, 161-176. [CrossRef]

16. Groot, H.L.; de Verhoef, E.; Nijkamp, P. Energy saving by firms: Decision-making, barriers and policies. Energy Econ. 2001, 23, 717-740. [CrossRef] 
17. Sandberg, P.; Söderström, M. Industrial energy efficiency: The need for investment decision support from a manager perspective. Energy Policy 2003, 31, 1623-1634. [CrossRef]

18. Thollander, P.; Ottosson, M. An energy efficient Swedish pulp and paper industry-exploring barriers to and driving forces for cost-effective energy efficiency investments. Energy Effic. 2008, 1, 21-34. [CrossRef]

19. Kannan, R.; Boie, W. Energy management practices in SME-Case study of a bakery in Germany. Energy Convers. Manag. 2003, 44, 945-959. [CrossRef]

20. Thollander, P.; Dotzauer, E. An energy efficiency program for Swedish industrial small-and medium-sized enterprises. J. Clean. Prod. 2010, 18, 1339-1346. [CrossRef]

21. Sardianou, E. Barriers to industrial energy efficiency investments in Greece. J. Clean. Prod. 2008, 16, 1416-1423. [CrossRef]

22. Soroye, K.L.; Nilsson, L.J. Building a business to close the efficiency gap: The Swedish ESCO Experience. Energy Effic. 2010, 3, 237-256. [CrossRef]

23. Stern, P.C. What psychology knows about energy conservation. Am. Psychol. 1992, 47, 1224-1232. [CrossRef]

24. Sa, A.; Paramonova, S.; Thollander, P.; Cagno, E. Classification of Industrial Energy Management Practices: A Case Study of a Swedish Foundry. Energy Procedia 2015, 75, 2581-2588. [CrossRef]

25. Sa, A.; Thollander, P.; Cagno, E. Assessing the driving factors for energy management program adoption. Renew. Sustain. Energy Rev. 2017, 74, 538-547. [CrossRef]

26. Turner, W.C.; Doty, S. Energy Management Handbook; The Fairmont Press: Lilburn, GA, USA, 2007.

27. Carbon Trust. Energy Management. A Comprehensive Guide to Controlling Energy Use. UK. 2011. Available online: http:/ / www.carbontrust.com/media/13187/ctg054_energy_management.pdf (accessed on 13 August 2016).

28. Worrell, E.; Bernstein, L.; Roy, J.; Price, L.; Harnisch, J. Industrial energy efficiency and climate change mitigation. Energy Effic. 2009, 2, 109-123. [CrossRef]

29. Caffal, C. Energy Management in Industry; Analysis Series, 17; Centre for the Analysis and Dissemination of Demonstrated Energy Technologies (CADDET): Sittard, The Netherlands, 1995.

30. Berglund, J.; Michaloski, J.; Leong, S.; Shao, G.; Riddick, F.; Arinez, J.; Biller, S. Energy efficiency analysis for a casting production system. In Proceedings of the Winter Simulation Conference, Phoenix, AZ, USA, 11-14 December 2011; pp. 1060-1071.

31. Vadiee, A.; Martin, V. Energy management strategies for commercial greenhouses. Appl. Energy 2014, 114, 880-888. [CrossRef]

32. Yin, R. Case Study Research: Design and Methods; Sage Publishing: Beverly Hills, CA, USA, 1994.

33. Yin, R.K. Case Study Research: Design and Methods, 3rd ed.; Applied Social Research Methods, Series 5; University of Plymouth: Devon, UK, 2003.

34. Holtzer, M. Implementation of IPPC directive in foundries. Metalurgija 2005, 44, 141-146.

35. The European Foundry Association. Available online: http://www.caef.org/downloads/kategorie.asp? kat=9 (accessed on 14 July 2017).

36. Duflou, J.R.; Sutherland, J.W.; Dornfield, S.; Herrmann, C.; Jeswiet, J.; Kara, S.; Hauschild, M.; Kellens, K. Towards energy and resource efficient manufacturing: A processes and systems approach. CIRP Ann. Manuf. Technol. 2012, 61, 587-609. [CrossRef]

37. Salonitis, K.; Zeng, B.; Mehrabi, H.A.; Jolly, M. The challenges for energy efficient casting processes. Procedia CIRP 2016, 40, 24-29. [CrossRef]

38. Thollander, P.; Karlsson, M.; Söderström, M.; Creutz, D. Reducing industrial energy costs through energy-efficiency measures in a liberalized European electricity market: Case study of a Swedish iron foundry. Appl. Energy 2005, 81, 115-126. [CrossRef]

39. Rohdin, P.; Thollander, P.; Solding, P. Barriers to and drivers for energy efficiency in the Swedish foundry industry. Energy Policy 2007, 35, 672-677. [CrossRef]

40. Swedish Foundry Association. The Homepage of the Swedish Foundry Association. 2004. Available online: http:/ / www.gjuteriforeningen.se/eng/index.htm (accessed on 14 July 2017).

41. Salonitis, K.; Jolly, M.R.; Zeng, B.; Mehrabi, H. Improvements in energy consumption and environmental impact by novel single shot melting process for casting. J. Clean. Prod. 2016, 137, 1532-1542. [CrossRef]

42. Thollander, P.; Mardan, N.; Karlsson, M. Optimization as investment decision support in a Swedish medium-sized iron foundry-A move beyond traditional energy auditing. Appl. Energy 2009, 86, 433-440. [CrossRef] 
43. Solding, P.; Thollander, P. Increased energy efficiency in a Swedish iron foundry through use of discrete event simulation. In Proceedings of the 2006 Winter Simulation Conference, Monterey, CA, USA, 3-6 December 2006; pp. 1971-1976.

44. Yin, R.K. Case Study Research: Design and Methods. In Applied Social Research Methods; SAGE: London, UK, 2002; Volume 5.

45. Jarża, S. Importance of energy management in foundries. Pol. J. Manag. Stud. 2011, 4, 166-173.

46. Cai, W.; Liu, F.; Xie, J.; Zhou, X. An energy management approach for the mechanical manufacturing industry through developing a multi-objective energy benchmark. Energy Convers. Manag. 2017, 132, 361-371. [CrossRef]

47. Wu, B.; Li, J.; Liu, H.; Zhang, Z.; Zhou, Y.; Zhao, N. Energy information integration based on EMS in paper mill. Appl. Energy 2012, 93, 488-495. [CrossRef]

48. Venmans, F. Triggers and barriers to energy efficiency measures in the ceramic, cement and lime sectors. J. Clean. Prod. 2014, 69, 133-142. [CrossRef]

49. McKane, A.; Scheihing, P.; Williams, R. Certifying Industrial Energy Efficiency Performance: Aligning Management, Measurement, and Practice to Create Market Value; Lawrence Berkeley National Laboratory: Berkeley, CA, USA, 2007.

50. Sustainable Energy Authority of Ireland (SEAI). Large Industry Energy Network (LIEN) Annual Report 2012; Sustainable Energy Authority of Ireland (SEAI): Dublin, Ireland, 2013.

51. International Organization for Standardization. Available online: https://www.iso.org/standard/23142. html (accessed on 14 July 2017).

52. International Organization for Standardization. Available online: https:/ / www.iso.org/files/live/sites / isoorg/files/archive/pdf/en/pub100329.pdf (accessed on 16 September 2018).

(C) 2018 by the authors. Licensee MDPI, Basel, Switzerland. This article is an open access article distributed under the terms and conditions of the Creative Commons Attribution (CC BY) license (http:/ / creativecommons.org/licenses/by/4.0/). 